\title{
Stakeholder's Attitude towards Withdrawing Social and National Education Textbooks from Jordanian Schools
}

\author{
Nader Sudqy Al-Refai \\ Assistant Professor of Islamic Education and Curriculum Design, \\ Islamic Studies Department, Yarmouk University, Jordan \\ Corresponding Author
}

Hadi Mohammed Tawalbeh

Professor of Social and National Education, Department of Curriculum and Teaching Methods, Yarmouk University, Jordan

DOI: https://doi.org/10.36941/jesr-2020-0o89

\begin{abstract}
This study explores stakeholders' reactions to the Jordanian Ministry of Education's decision to withdraw the 'social and civics education' textbooks for students in the first three grades (containing children aged 6 to 9) in the academic year 2013-2014. A qualitative survey was undertaken in the year following the textbook withdrawal, of how various stakeholders reacted to this decision. The participants of the study $(N=70)$ were people affected by the textbook withdrawal, namely headteachers, classroom teachers, supervisors, and social studies teachers along with parents, and young children during the years 2015-2016. The participants were selected by the convenience sampling method from the provinces of Irbid, Jerash, Al-Mafraq, Bani Kenana and Al-Ramtha. The overt reasons for the textbook withdrawal were: (a) to reduce the weight of students' schoolbags; (b) to focus more on mastering reading, writing, and math skills; (c) to decrease the large number of subjects studied by young students; and (d) to avoid an overlap of topics that were sometimes found repeated in the social/national textbooks and those of other subjects. Those interviewed endorsed these Ministerial decisions, but also expressed several reservations. This article draws upon a longer document, which has formed part of the democratic consultation process which marks a Muslim culture.
\end{abstract}

Keywords: Social Studies Curriculum, Citizenship Education, Textbook Development, Weight of Schoolbags, Democratic Consultation

\section{Introduction}

The present research begins by reviewing the challenges to the successful teaching of civics and social studies (citizenship education), which has the goal of fostering attitudes and skills in young people, in ways which will make them 'ideal citizens' within Jordan. Jordan is a middle-income country with a majority population of Muslims, who would be expected to live according to Islamic values and observe Islamic tradition. Despite the influx of refugees and other international disruptions, Jordan has maintained its reputation as a peaceful and relatively prosperous democratic society in the 
Middle East (El-Anis, 2011).

Educational progress requires paying careful attention to the improvement of qualitative inputs for all aspects of the learning and teaching process, which includes the development of school curricula to reflect the latest international attitudes and opinions (Al-Tete, 2008). For education to be successful, curricula must reflect systematic research findings that offer reliable advice, so that students may acquire knowledge which helps them to cope with real-life challenges.

Mur'ee and Al Healah (2004) point out that school curricula are one of the most important factors of education, and guide learning procedures for both the teacher and the student. School textbooks are usually central to curricula and primary sources for student learning, a guideline for teachers to develop their teaching plans and regulate the learning and teaching process, and a mechanism for students to achieve their envisaged goals (Al-Tete, 2008; Oates, 2014; Oruç, 2015). Oruç (2015) argues: "Textbooks are important sources that determine what students can learn and what teachers can teach in the teaching and learning process; they are the most fundamental source for the teacher and student" (p. 127). For this reason, no matter how much the sources for learning materials may vary, the textbook usually remains an important factor in learning process outcomes and may have a significant effect on the quality of the educational process (Al-Hashimi \& Ateah, 2011; Baştürk, 2005).

National education in Jordan is linked to social studies and their related curricula, and this education aims at helping students to identify with their country of origin and its history, which is one of a developing Islamic nation with a colonial past. Such education teaches students to learn about their community and encourages them to work towards its development and prosperity (Abu Deyah, 2011; Alayan et al., 2012).

The international literature provides intellectual and research-based support for the developing Jordanian model of teaching and learning the 'social studies' curriculum, in a variety of applications and settings. Miller and Neese (1997) confirmed that imparting concepts of citizenship to students most effectively occurs by providing learning situations that enable students to be immersed in the concept of community service from an early age. Schools can achieve this by making direct and contemporary associations between learning activities and community action.

This approach is not without critics. The vagueness of the goals of national and civic education may contribute to the possibility that some (perhaps many?) students find the activities boring, aimless, and even time-wasting, especially when such studies are heavily dependent upon the memorization of dates, names, facts and figures that students find difficult to relate to and link to their own everyday lives (Evans, 1989). For these reasons, social studies textbooks have evolved in directions that attempt to capture the interest of students and stir their enthusiasm for the subject (Mathison \& Fragnoli, 2006).

Al-Sheikh (2001) outlines some reasons for criticisms which citizenship education programs face when (a) the subject focuses on theoretical and abstract information; (b) it neglects current events and pressing concerns in students' lives, and (c) there is too much focus on memorization of abstract concepts. Habib (2003) also argues that the reason for students' lack of interest in these subjects is that teachers often instruct them in a traditional manner, focusing on 'indoctrination', rather than on the principle that pupils should "live what they learn" (Harris \& Nolte, 1998). While the classic text by Harris and Nolte is directed towards parents, it emphasizes the fact that teachers of young children often play a role similar to that of parents, and their elders should encourage good behaviours (oftenreflecting religious values) in which children act in positive ways in in both the family and community environment.

These are some grounds for advocating the improvement of the social studies curriculum generally, and national and civic education specifically. As Blaser (2011) pointed out, the main goal of national and civic education is to produce a good citizen: but meeting this goal is difficult without designing activities and teaching methods that employ active forms of service-learning. This actionoriented approach is important because it enhances students' positive behaviours, their community collaboration, and their ability to make sound decisions in interpersonal and group settings in family 
and community (Ross, 2006).

One issue that has to be faced is that national and commercial interest groups may seek to dominate the content of online supplementary materials for social studies textbooks (e.g. TCI, 2017), a problem identified in Western cultures by Giroux (2008). For nations with Muslim-majority populations, social studies texts and supplementary materials need to be framed in a way that is culturally relevant to Islam (Memet \& Turkham, 2017). Tonga (2016) has developed a useful social studies curriculum model within the context of a mainly-Muslim nation (Turkey), adapting traditional Western concepts of social studies in the following way:

\begin{tabular}{ll} 
Western Model & Islamic Model \\
\hline Good Citizen & Good Moral Behavior \\
Values & Values \\
Being scientific & Islamic Sciences \\
Honesty & Trust \\
Charity & Zakat \\
Patriotism & Love of Fellow Humans \\
Women's Rights & Women's Equality \\
Human Rights & Human Honor \\
Respect of Differences & Tolerance of All \\
Sensitivity to Environment & Love of Nature \\
Democracy & Continuous Consultation \\
\hline
\end{tabular}

Source: Adapted from Tonga, 2016

High quality social and national education textbooks (and supplementary online materials) should aim to promote affiliation and belonging to humanity, investigating the examples of noble figures in history (such as the Prophets of Islam), and classic stories and experiences of famous people. Providing them with such examples would help to develop the learners' ability for critical thinking, analysis, and understanding important definitions surrounding collaboration, competition, and social advancement of self and others. In addition, social and national education goals must aim to enlighten students about positive qualities of modern civilization, and the promotion of international collaboration based on mutual respect, both ancient and modern (Laughlin \& Hartoonian, 1995; Merryfield \& Subedi, 2006). There is now a welcome trend toward teaching "universal social studies" which focuses on aspects of civilized living in all continents (Karakus \& Turkhan, 2017).

This relates to what Khan (2004) regards as the implementation of social and national educational goals which lead to educating students in becoming active citizens and preparing them to take on useful adult roles. This is of importance to non-migrant children, and is even more crucial to migrant children in any community. (Al-Refai \& Bagley, 2008). Civic education programs in all cultures must also educate students about behaviour towards minority and disadvantaged groups, and the role which particular religious groups can play in encouraging positive citizenship roles (AlRefai \& Bagley, 2012).

Furthermore, social studies must emphasize positive interactions with ongoing daily events in one's country, and in the wider Arabic community in all areas of life. These subjects will, according to critics, fail to achieve their goals (of producing better citizens) unless they produce a relationship between their educational content and appropriate practical applications. According to this argument, the social studies citizenship curriculum would be more effective in achieving identified goals by practising the educational content outside of the classroom (Cengelci, 2013).

National and civic education requires learners to actively participate in the community's positive activities in order to become responsible citizens. This curriculum must help students to internalize the values and actions that define good citizenship (Lopes et al, 2009), a concept that aligns with Wade's argument (2008) that citizenship is to a strong extent based on community labour. From that, we may extrapolate that teaching national and civic education will be ineffective 
without civil cooperation. Furthermore, as Kaur (2004) points out, learning social education means inducing appropriate and measurable changes in students to improve their behaviour.

On the other hand, teachers may face many challenges in teaching social and national education curricula when the learning process is heavily reliant upon the traditional methods of memorization and indoctrination. Milton (1993) showed that students in some cultures spent extensive amounts of time memorizing content, without links to practical application. Another challenge standing in the way of successful student achievement in these subjects is the domination of traditional, and sometimes punitive, teaching methods which may result in the students' negative perceptions of the content. This most often leads to feelings of boredom and indifference, or even rejection of the concepts taught, as well as a lack of awareness of the issues raised therein (John, 2005).

Based on these arguments, it is not enough to cover subjects related to citizenship in classrooms only, without also including appropriate practical experiences (Geboers et al., 2015). This fits with Hoffman (2000), who felt that embodying concepts of positive citizenship, including justice, altruism, freedom, loyalty, respect for the law, and respecting cultural diversity and the welfare of others, does not only come from curricula and the goals and content they contain, but also requires learning situations rich in experiences that fall outside of the classroom's borders, within the broader school environment, and in the family and neighbourhood settings.

National educational decisions should follow sound methodological procedures in which all concerned parties should participate in 'national dialogue' conferences to gain a consensus for curricular reform, discussing ideas for curriculum development before they are adopted, as well as conducting ongoing reviews. This is recommended to avoid any new decisions being repealed or abandoned by practitioners, which would indicate that they were not thoroughly and objectively studied prior to or soon after their introduction. Decisions related to social and national education are considered critical because of their relationship to national identity and the values unifying citizens (Schulz et al. 2008; Geboers et al. 2012). This is based on the idea that citizenship education reflects national values and loyalty to the wider community. Lack of a coherent and meaningful citizenship curriculum could even threaten a country's national identity.

Past studies have explored aspects of curriculum relevant to our current agenda of social studies curriculum reform in Jordan, including Youssef (2015) who aimed to define the basic teaching proficiencies present in social studies teachers' education. Obeidat and Tawalbeh's Jordanian work (2014) highlighted the challenges faced by those both teaching and studying history, revealing that $78 \%$ of teachers of that subject did not study or teach history based on their own values and perceptions of the discipline. Nevertheless, well-trained history teachers in that study made some suggestions to overcome these challenges, such as enriching history books with activities and educational media, using Book Theater in a dramatic fashion, and interacting with websites at the end of every lesson to allow the acquisition of additional information.

Abu Saninah's (2007) Jordanian study investigated the challenges faced by elementary grade teachers in teaching the social and national education curriculum and found that teachers identified numerous challenges and criticisms. Abu Saninah (2011) further examined the extent to which social and national education teachers encouraged their students to practice active learning in primary classes. The results indicated that the total extent of encouragement and positive involvement with the national history curriculum was generally high, and there were no statistically significant differences attributed to variables like gender, social status, or prior educational experience in comparing teachers' commitment. Any differences were explained by teachers' qualifications in favour of those with a bachelor's degree, and place of residence, in favour of those living in cities.

Analyses concerning the teaching of social and national education studies by classroom teachers in Jordan have been undertaken by Youssef (2015) and Abu Saninah (2007, 2011). Youssefs (2015) study focused on educational advisors, while Abu Saninah's (2011) work examined the methods used in teaching social and national education, particularly active learning. Obeidat \& Tawalbeh's (2014) work considered the difficulties in studying history in Jordanian schools and the possibilities for 
curriculum reform. This published literature has shown changes in how teachers present "social studies" to their students (in both Western and Islamic cultures), with a growing focus on complex methods of information transmission using multimedia technology, themed activities, and more focus on becoming "good citizens" in relevant ways, inside the classroom, at school and in wider society.

Textbooks are still used, however, and some teachers remain faithful to traditional texts, and traditional types of instruction and assessment, even for children in the early years of elementary schooling. Nevertheless, the advice emerging from this literature review is that textbooks in and of themselves can by no means encompass the whole of the social studies curriculum. Teaching values requires practice as well as theory, and new forms of electronic media may supplement traditional media resources.

Every student in Jordan has, traditionally, studied social studies, values, and civics education from the first grade of the primary stage through to the second grade of secondary education. Declared educational goals are to improve the basis of knowledge, as well as to foster the positive emotions and behaviours of students. This is achieved by including lessons related to people, their families, their environment, their country, current problems and obstacles facing them, historical figures that they should revere, and the learning of positive roles and responsibilities as young citizens (Alayan et al., 2012).

The social and national education curriculum of 1961 is considered to be an important foundational curriculum, receiving constant attention and development from the Ministry of Education as a guide since that time. The Ministry of Education did not initially specify any social studies textbooks for the first and second grades, but after the first Education Development Conference of 1987 , a series of textbooks was allocated to each grade of the primary stage, which extends from first to fifth grade (Mansour, 2010).

It should be noted that the nomenclature used for the social studies curriculum is "social and national education". It is recognized that the word "social" preceding the word "national" has significant implications, including the importance of concentration on improving oneself, and one's behaviour towards others. This includes socializing 'righteous people' who are thoroughly prepared to take on a variety of roles, imparting certain pro-social behaviours to individuals, and teaching students to practice positive civic behaviours when interacting with their environment, and with others in their community (Mansour, 2010).

The problem of heavy school bags: a review of medical literature

The Western observer of schools in developing countries is often surprised at the practice of children carrying a heavy load (usually in a backpack) of books from home to school and back each day. This reflects two factors: lack of security and safe storage space in the school itself; and a traditional belief that the physical burden of carrying books is somehow part of the discipline of learning their content.

We have located more than 12 well-conducted studies of the burdens and health hazards of heavy school backpacks for elementary school children (reviewed by Janakiraman et al., 2017). These include controlled studies of pain and muscular-skeletal distortion in children with, and without heavy backpacks. The evidence from countries in Asia, the Middle East, and Africa (e.g. Al-Saleem et al., 2016; Dianat et al., 2013 \& 2014; Mwaka et al., 2014) is unequivocal. Carrying a backpack which exceeds 10 to 15 per cent of a child's body weight for several months results in chronic pain of upper and lower back, and muscular-skeletal distortions which could be permanent. In all of the studies reviewed, more than 50 per cent of all children carried more than 15 per cent of their body weight on their backs or shoulders. Younger children and those who walked to school for several kilometres suffered the most chronic pain and skeletal distortion.

\section{Research Problem and Questions}

At the beginning of the academic year 2013-2014, the Jordanian Ministry of Education withdrew the 
prescribed textbooks in this subject for the first three grades, while keeping social and national education in the course schedule. While the decision was said to be in the interests of students, schools, and the country itself, no specific reasons were given by the Ministry, so it is relevant to ask stakeholders for their perceptions of these changes. The views of advisors and principals are particularly important in understanding why these changes were made since their views were most likely to have influenced the ministerial decision. At the time, some traditional voices did advance criticism of this decision, and it is important in an era of social change to elicit stakeholder's views, which has not been done previously. The present study aims to answer the following main question: what are the reasons behind adopting this decision from the concerned parties' point of view?

\section{Methodology}

The researchers began implementing the study a year after the ministerial decision took effect to withdraw the prescribed, compulsory social and national education textbooks for the first three grades of elementary schooling, for children aged 6 to 9. The lengthy Arabic-language report arising from this appraisal (of which this article is a summary) was part of the consultative process which often marks Islamic democracy (Tonga, 2016), in which managers and decision-makers consult their constituencies in making and evaluating administrative decisions.

This consultative case study had the dual aim of both elucidating some of the reasons for the Jordanian Ministry of Education's decision to withdraw textbooks from the youngest students (aged 6 to 9), and also to inform the Ministry about how different groups of stakeholders viewed these changes, their causes and consequences.

The researchers have used qualitative methods, which fitted the nature of the inquiry and the groups of people participating in the study. Additionally, the researchers themselves, as academics and government advisors, hold value positions that could influence research outcomes. This exploratory study, using semi-structured interviews, included firstly educational advisors and school principals: the two groups whose feedback and communication with the Ministry of Education was most likely to have influenced the decision to withdraw the bulky textbooks from the social studies curriculum for young children. Other stakeholder groups interviewed were parents, classroom teachers, social studies teachers, and students of the first three grades, and their parents in representative school districts in Jordan.

The semi-structured interview model is an accepted method of qualitative research in surveys for exploring how different groups feel about, for example, administrative decisions (Gray, 2014). The "administrative decision" explored in the present study was that by the Jordanian Ministry of Education to withdraw textbooks for the first three grades of schooling (children aged 6 to 9), following consultation with educational advisors (administrators and school inspectors), and headteachers.

Participants were selected (in 2015-2016) in a systematic but non-random manner. Table 1 shows the distribution of the study's participants based on their occupations.

Table 1: The distribution of the study's participants based on the variable of occupation

\begin{tabular}{lc} 
Occupation & Number of participants \\
\hline School Principals & 8 \\
Classroom Teachers & 16 \\
Educational Supervisors & 6 \\
Social Studies Teachers & 10 \\
Students' Parents & 20 \\
Students of the first 3 grades & 10 \\
\hline Total & $\mathbf{7 0}$
\end{tabular}


The initial interview questions were checked by 14 arbitrators specializing in social studies. The first and most structured part of the interview consisted of two main questions and six sub-questions. The reliability of responses to questions in a qualitative interview schedule is difficult to judge and could only be established through re-interviewing the original subjects or comparing results with those from a fresh sample. The methodology here follows the procedures outlined by Gray (2014) on the qualitative methodology for survey analysis.

The semi-structured format then allowed participants the chance to talk about whatever they wanted across the topic, especially the students of the first three grades and their parents, who were not accustomed to this kind of professional inquiry. The researcher then listened to the recordings of the extended interviews, in order to categorize responses that went beyond the semi-structured questions.

\section{Results and Discussion}

Findings in this section are based on the principal benefits perceived by respondents for the withdrawal of the basic textbooks and then replacing them with curriculum guidelines for use by teachers. The two most important groups, who apparently guided the ministerial decision, are the educational advisors, and the headteachers. In the later part of the semi-structured interviews, respondents volunteered other reasons why they approved of the textbook withdrawal. Other respondents expressed their regrets or reservations.

A frequently repeated reason for approving the withdrawal policy stated by educational supervisors and others for withdrawing social and national education textbooks was that of reducing the weight of schoolbags - an opinion confirmed by the responses of the other stakeholder groups. This reflects the societal pressures calling for the reduction of the weight of schoolbags. This is noteworthy due to the increasing amount of medical and clinical evidence confirming the negative effects of schoolbag weight on children's health status in general and on the increase in vertebral column defects specifically (Janakiraman et al., 2017). This evidence, as well as popular opinions which our survey has confirmed, certainly increased pressure on the Ministry to take action to decrease the effects of this problem, as most child health experts indicate the long-term detrimental effects of carrying heavy schoolbags (Al-Saleem et al., 2016). This research evidence shows that carrying backpacks with a weight of more than 15 per cent of a young child's body weight often leads to chronic back pain, and for some, permanent spinal deformities.

Responses were elicited on a "forced choice" basis in the first, most structured part of the questionnaire, so an issue chosen had to have high salience for the groups questioned. There is more agreement than disagreement, in general, on the choices made by the different groups. The second most frequently cited reason for approving the textbook reform was that it allowed more time for the acquisition of Arabic and mathematics ability in the early years. Obviously, if pupils are to benefit from a textbook, they must be able to read it. The response, "The unimportance of social and national education in this stage," was offered only once. This can be explained by the predominant belief that there is enough time to teach social and national education content starting at the fourth grade: many ideas concerning social and national education are repeated in other subjects, especially in Arabic, Islamic Education, Science, and Art, through what is called horizontal integration in education.

When we turn to the responses given in the less structured part of the interview, in which informants were free to be more discursive about the issues, a number of different opinions emerged.

The data revealed that educational supervisors strongly agreed with the decision to withdraw the social and national education textbook. In this view, social and civic education is so clearly a topic that crosses disciplinary boundaries, that relevant information can be acquired from sources other than from specialized textbooks. This also could be attributed to giving Arabic and math more importance, especially considering declining proficiencies in reading, writing, and arithmetic skills. However, supervisors did advocate the introduction of social studies and civics education at an early 
age, since they believed that citizenship and patriotic education in childhood were so crucial that it should be introduced, if not by textbooks, then by means of new curriculum guidelines used by teachers.

Most of the interviewed school principals advocated retaining social studies and civics teaching at an early age since they were strongly in favour of imparting social values to the next generation, and the students' needs for perceptible and tangible information. Some said that the withdrawn books had been a source of learning, rich in information, were considered unique in nomenclature (concerning social and national education), and were closely related to students' identity needs.

However, some principals wholeheartedly agreed with the decision to withdraw the first three grades' textbooks and replace them with the teacher's guide. The most significant reason was the overlapping of the textbook content with other subjects like Islamic Education. Moreover, stories, class situations, the national anthem, national celebrations, and voluntary community campaigns could well, according to respondents, promote citizenship values in students. The children could easily look for more citizenship-building information from other sources (including electronic media), once they had successfully mastered reading and writing skills.

Most principals observed that students of the first three grades needed to master the skills of reading, writing, and arithmetic, and took into consideration the affirmation of the Ministry of Education from its educational advisors' field reports (affirmed by the present group of advisors in the study in hand) that students are often weak in these skills: the advisors' initial report to the Ministry had pointed to the fact that many students cannot fluently read Arabic letters, words or phrases until the ages of about 8 or 9 . Under those circumstances, requiring a young child who cannot read well to study a heavy textbook is hardly justified. Some respondents also suggested that the breadth of the curriculum detracted from the crucial tasks of becoming literate and numerate and therefore social studies/civics should be introduced as a formal subject only in later years. At this stage, principles of Islamic education which emphasized good conduct and the helping of others should be sufficient.

Most of the interviewed classroom teachers unambiguously agreed with the decision to withdraw the social education textbooks for the first three grades. In their general view, social and civic education topics could be embedded in other school subjects. In addition, the teachers said that they could focus on this content in daily situations and experiences, conversations and discussions. This also led to most supporting the content of the teacher's guide, which specifies the teaching of various national and moral values. Most felt that these guides were a better way of engaging the interest and motivation of students, in the hands of dedicated and motivated teachers, especially since the new procedures allowed more freedom for the teacher who, like the students, had escaped from 'burdensome' and sometimes irrelevant textbooks. Now, many teachers said, they could focus on practical issues and exercises, rather than on theoretical ideas which were beyond the comprehension of children aged 9 or under. One approving teacher said:

"The Ministry aims to prepare a generation that masters all three skills. The guide + an excellent teacher $=$ the best and most beautiful course for social education. It is a decision which is convenient for classroom teachers, the period is now better, and improves listening, discussion, and conversation."

On the other hand, a minority had reservations about the decision to withdraw the social and national education textbooks. This group generally felt that instilling information about Jordan's history, customs, and traditions should begin in early childhood, with the direction of a formally prescribed textbook. Some also defended the textbooks because they contained pictures (mostly in colour), with suggested activities for the students. Therefore, they argued, the new teacher guide was appropriate for the teacher, but not necessarily for the students.

Among the Social Studies teachers interviewed, less than half wholeheartedly supported the decision to withdraw the textbooks. That the majority were nominally in favour of withdrawal might be explained by their conviction as specialists that acquiring concepts of national identity had little 
relationship to the presence of the textbook: rather, these values are acquired by a more dynamic and less perceptible curriculum. They emphasized the importance of concentrating on what the teacher says and does and his or her embodiment of the national spirit by way of conversation and discussion. This was also linked to the perceptions of social studies teachers that the goals of social and national education could be instilled by designing extracurricular activities, organizing field trips, hosting important people as guests, designing posters, organizing voluntary campaigns, community activities, and school ceremonies. As one teacher observed:

"Teachers should continue practising their positive roles, which are imperceptible. Social education is a practical subject. Citizenship could be instilled by extracurricular activities."

On the other hand, a significant number of Social Studies teachers had some reservations concerning the decision to withdraw social and national education textbooks. This is possibly explained by the association between the withdrawn_textbook and the status of their speciality. The absence of the book might "belittle" the subject of social and national education, with other subjects being seen as more important than social and national education, even though this decision succeeded in strengthening student's reading and writing skills. As one teacher observed:

"The book attracts students with pictures and maps. The absence of the textbook leads to ignorance about nationalist concepts and neglecting to teach the subject well. Social studies are food for the soul and mind."

In reflecting on the decision to withdraw textbooks, possible explanations from the parents included their beliefs that children's mastery of reading, writing and arithmetic skills at this stage was very important, and the decision might help them free some time for acquiring mastery of basic subjects. According to one parent, "The previous book is hard and exceeds their level."

Some parents believed the desired goals of social and national education should focus more on emotional interactions with the teacher and with peers and the wider society, rather than being based merely on factual, textbook information. Some also thought that the new method of teaching civic education would be more fun and beneficial due to its inclusion of more support and development for children's ability to analyze concepts, use critical thinking, and practice listening skills. On the other hand, some parents had idiosyncratic perceptions regarding citizenship education, which they said could not simply be taught by the teacher or by a textbook alone. Instilling citizenship concepts and behaviours in the minds of children required, in this view, real collaboration beginning within the family, because the family is the primary source of children's moral education. One parent, approving the textbook withdrawal, observed:

"What is more important is that my son reads and writes, and focusing on emotions is more important than the information in national education. The schoolbag is very heavy, and it breaks one's resolve."

However, some parents thought that school textbooks allowed parents to follow up on what their children learned, enabling them to help their child prepare for lessons in advance. One parent who had reservations about the textbook withdrawal said:

"The presence of the book forces the teacher to teach it and the students to study it. I am a mother who majored in Math, but students must have a foundation in national education, the same as in Arabic and Math. The textbook enters every Jordanian home and is read by every father... mother and child. What benefit do we get from their decision if our children have a replacement dossier? No, I swear to God the textbook is more forgiving and more beautiful. Everything but nationalism, the child forgets what he learns in class and our community is suffering from an ethics crisis. We are afraid of a new generation that knows nothing about its nation."

The results of our interviews with students (children aged 6 to 9) could not provide an accurate 
measurement of the "social desirability" effect, and the children often made efforts to provide "correct" or "pleasing" answers. Given this problem, many students did express support for the decision to withdraw the social and national education textbooks. This could be explained by the students being relieved of the burden of heavy school bags, the reduction in the amount of homework assigned to them, and the new curriculum making civics education classes "more fun". One approving student said:

"We were relieved from carrying the textbooks. I started having to pay attention to what the teacher was saying to understand the lesson. We have more Arabic and Math periods. I enjoy the teacher's explanation."

On the other hand, a number of students did say they missed the old textbooks -reasons given were that they could share the preparation with a parent, and could also access the pictures in the book, some of which invited the student to complete in colour. They also remembered activities which the textbook had suggested to be undertaken in the classroom. One student said:

"We learn a lot from the textbook's pictures. I do not like studying without a book. I cannot revise the information. The teacher replaces social studies periods with other subjects. We do not participate in the class because we do not know the lesson."

\section{Conclusions and Recommendations}

This study has explored the likely reasons behind the Ministry of Education's decision to withdraw the social and national education textbooks for the first three elementary school grades in Jordan. The stakeholders' main reasons (which were likely to have been similar to the opinions received by the Ministry in the process of "consultative democracy") for accepting the withdrawal were: (a) to reduce the physical weight of young children's burdensome schoolbags; (b) to focus on mastering reading, writing, and math skills in the early years; (c) to lessen the large number of subjects studied by the young students; and (d) to avoid an overlap between topics in social/national textbooks and topics in the other subjects.

The stakeholders interviewed approved the Ministerial decision on two main grounds: reduction in the weight of school bags; and creating more time in the early grades for the learning of basic subjects. These two main reasons held across all of the stakeholder groups. In further responses in the semi-structured interviews, some concerns were expressed, reflecting a certain nostalgia for the withdrawn textbooks, and concerns that national and civic education was in danger of being neglected, or even devalued. This 'conservative anxiety' was offset by the expectation among many informants that new ways of teaching civics and social studies, and integrating it with other lessons, would be valuable in the long run. What is now needed is the type of study reported from Europe by Al-Refai and Bagley (2008) on citizenship education in secondary schools, examining how Jordanian adolescents have acquired, and act out, the concepts of "the good citizen". Other research may involve a follow-up of the young students interviewed in this study, examining their acquisition of the citizenship syllabus concepts under the new curriculum.

In conclusion, we suggest that making important educational decisions should occur according to procedures in which all concerned parties participate in open, national dialogue conferences to discuss ideas before they are adopted. This is recommended to avoid the possibility of educational innovations having to be withdrawn or repealed when the majority of stakeholders are opposed to such changes. The present research has shown that, in the main, stakeholders did support the Ministry's decisions on textbook withdrawal.

Decisions related to social and national education are considered critical because of their relation to the national identity and the values unifying citizens. The curriculum also addresses various challenges in the world today (Alayan et al., 2012), especially the current events surrounding the Arab region, which urge that close attention is paid to making the next generations aware of 
important social issues and facilitating a culture of loving their nation and loyalty to their community.

Furthermore, emphasis must be placed on the preservation of the capabilities of social and national education textbooks for older children that focus on the history of human civilization, and which help revive hopes of unity and feelings of love, forgiveness and tolerance, welfare, acceptance of others, and pride in national identity.

Based on the results of this study, the authors have identified a number of points that could ameliorate teaching of this subject matter, and therefore make the following recommendations:

1. The use of 'electronic books' and web-based material for social and national education.

2. Keeping the social and national education textbooks for the first three grades as reference books inside the classroom, if security conditions will allow. This will enable social studies and other teachers to use multiple teaching resources.

3. Designing further activity guides, both paper and electronic, for the student in social and national education - containing games, drawings, simulations, puzzles, videos, scientific applications.

4. Increasing the rate of educational supervisor visits to the classroom to support teachers, and to increase training workshops and teacher training curricula in this field.

\section{References}

Abu Deyah, A. (2011). Current Methods in Teaching Social Science, Amman: Dar Osamah for publication.

Abu Saninah, A. (2007). The Problems of the Social and National Education Curriculum for the First Three Basic Classes (I, II, III) from the Perspective of the Teachers of These Classes in UNRWA Schools in Jordan, Palestinian Educational Journal, 1, 42-75.

Abu Saninah, A. (2011). The Degree of Encouraging Pupils of the Lower Elementary Stage at UNRWA Schools by Social Studies Teachers in Jordan to Practice Active Learning from their Perspectives, Hebron University Research Journal, Humanities, $7(2)$, 57-78.

Alayan, S., Rohde, A., \& Dhouib, S. (Eds.). (2012). The Politics of Education Reform in the Middle East: Self and Other in Textbooks and Curricula. Oxford: Berghahn Books.

Al-Hashimi, A, \& Ateah, M. (2011). Content Analysis of School Curricula, Amman: Dar Safa For Printing, Publishing \& Distribution.

Al-Refai, N. \& Bagley, C. (2012). Muslim Youth and Citizenship Education: Idealism, Islam, and Prospects for Successful Citizenship Education. In F. Ahmed \& M. Siddique Seddon (Eds.) Muslim Youth: Challenges, Opportunities and Expectations (pp. 170-181). London: Continuum Books.

Al-Refai, N. \& Bagley, C. (2008). Citizenship Education: The British Muslim Perspective. Leiden: Brill - Sense Education Series.

Al-Saleem, S. A., Ali, A., Ali, S. I., Alshamrani, A. A., Almulhem, A. M., \& Al-Hashem, M. H. (2016). A Study of School Bag Weight and Back Pain Among Primary School Children in Al-Ahsa, Saudi Arabia. Epidemiology (Sunnyvale, Calif.), 6(1).

Al-Sheikh, R. (2001). Interpretation of the Course of History, Theories in the Philosophy of History, Cairo: Human Sciences and Social Studies Series.

Al-Tete, M. (2008). Social Education and its Teaching Strategies, Amman: Dar Educational World for Publication.

Baștürk, M. (2005). Ders Kitaplarının Tarihçesi. Konu Alanı Ders Kitabı Incelemesi, 13-36. Ankara: Pegem A Yayınları.

Blaser, T. (2011). From the Classroom to the Community: Safe and Caring Communities. The Iowa Council for the Social Studies Journal, 24 (1), 7-19.

Cengelci, T. (2013). Social Study Teachers Views on Learning Outside the Classroom. Educational Science: Theory E Practice, 13 (3), 1836-1841.

Dianat, I., \& Karimi, M. A. (2014). Association of Parental Awareness of Using Schoolbags with Musculoskeletal Symptoms and Carrying Habits of Schoolchildren. The Journal of School Nursing, 30 (6), 440-447.

Dianat, I., Javadivala, Z., Asghari-Jafarabadi, M., Asl Hashemi, A., \& Haslegrave, C. M. (2013). The Use of Schoolbags and Musculoskeletal Symptoms Among Primary School Children: are the Recommended Weight Limits Adequate? Ergonomics, 56 (1), 79-89. 
El-Anis, I. H. (2011). Jordan and the United States: The Political Economy of Trade and Economic Reform in the Middle East. London: Tauris Academic Studies.

Evans, W. (1989). Lessons History: Teacher and Student Conceptions of the Meaning of History. Theory and Research in Social Education, 1 (3), 203-225.

Geboers, E., Geijsel, F., Admiraal, W., \& Ten Dam, G. (2012). Review of the Effects of Citizenship Education. Educational Research Journal. DOI: 10.1016/j.edurev.2012.02.001

Geboers, E., Geijsel, F., Admiraal, W., Tem Dam, G. (2015). Citizenship Orientations and Knowledge in Primary and Secondary Education. Social Psychology of Education, 18(4), 749-767. DOI 10.1007/s11218-014-9265-7

Giroux, H. A. (2008). Education and the Crisis of Youth: Schooling and the Promise of Democracy. In: The Educational Forum (Vol. 73, No. 1, pp. 8-18). Taylor \& Francis Group.

Gray, D. (2014). Doing Research in the Real World. $2^{\text {nd }}$ Edition. London: Sage.

Habib, M. (2003). Current Trends in Teaching Thinking: Future Strategies for the Third Millennium, Cairo: Arab Thought House.

Harris, R., \& Nolte, D. L. (1998). Children Learn What They Live. Workman Publishing.

Hoffman, M. L. (200o). Empathy and Moral Development: Implications for Caring and Justice. Cambridge, England: Cambridge University Press.

Janakiraman, B., Ravichandran, H., Demeke, S., \& Fasika, S. (2017). Reported Influences of Backpack Loads on Postural Deviation Among School Children: A Systematic Review.Journal of Education and Health Promotion, 6, May.

John, F. (2005). Engaging Students in Learning History. Canadian Social Studies, 52 (2), P264- 278.

Karakus, M., \& Turkkan, B. T. (2017). Examination of Social Studies Curriculum and Course Books in the Context of Global Citizenship. Universal Journal of Educational Research, 5 (3), 472-487

Kaur, B. (2004). Teaching of Social Studies New Trends E Innovations. New Delhi, India: Sage Publications.

Khan, M.A. (2004). Teaching Social Studies in Secondary School. New Delhi, Commonwealth Publications.

Laughlin, M. \& Hartoonian, H. (1995). Challenges of Social Studies Instruction in Middle and High School. New York: Harcourt Brace College Publisher.

Lopes, J., Benton, T., \& Cleaver, E. (2009). Young People's Intended Civic and Political Participation: Does Education Matter? Journal of Youth Studies, 12(1),

Mansour, A. (2010). Change of School Curriculum and its Relation to the Social, Political, and Economic Changes in Jordan (1950-200o), Amman: Dar Konoz Publishing \& Distribution.

Mathison, S., \& Fragnoli, K. (2006). Struggling for Good Assessment in Social Studies Education. The Social Studies Curriculum: Purposes, Problems, and Possibilities, 3, 197-215.

McGuire, M. (2007). What Happened to the Social Studies? The Disappearing Curriculum. Phi Delta Kappa, 88(8), $620-624$

Memet K. M. \& Turhan, B. (2017). Examination of Social Studies Curriculum. Universal Journal of Educational Research 5 (3): 472-487.

Merryfield, M. M., \& Subedi, B. (2006). Decolonizing the Mind for World-centered Global Education. The Social Studies Curriculum: Purposes, Problems, and Possibilities, 283-295

Miller, G \& Neese, L. (1997). Self-Esteem and Reading out: Implications for Service Learning. Professional School Counseling, 1, 29-32.

Milton, M. (1993). Perspectives from the Past Present on Moral, and Citizen Education in Poland. Journal of Moral Education, 12 (13), P225- 233.

Mur'ee, T., Al Healah, M. (2004). Modern Educational Curricula: Its Concepts, Elements, Foundations, and Processes. $4^{\text {th }}$ Ed, Amman: Dar Al Massira For Publishing, Printing \& Distribution.

Mwaka, E. S., Munabi, I. G., Buwembo, W., Kukkiriza, J., \& Ochieng, J. (2014). Musculoskeletal Pain and School Bag Use: A Cross-sectional Study Among Ugandan Pupils. BMC research notes, 7 (1), 222.

Oates, T. (2014). Why Textbooks Count, A Policy Paper. Cambridge University. Retrieved from http://www.cambridgeassessment.org.uk/Images/181744-why-textbooks-count-tim-oates.pdf

Obeidat, H., \& Tawalbeh, H. (2014). Difficulties in the Study of History and the Suggested Solutions. Journal of AlQuds Open University for Research and Studies, 34 (2), 275-298.

Oruç, Ş. (2015). Sources Used in the Preparation of the Social Studies Textbooks to Study in Elementary School. International Online Journal of Educational Sciences, 7 (1), 127-133.

Ross, E. W. (2006). Remaking the Social Studies Curriculum. In E.W. Ross (Ed). The Social Studies Curriculum: Purposes, Problems, and Possibilities, (pp 319-332) 3rd Edition. New York: State University of New York.

Ryan, F. (2010). Social Learning and Teaching Social Studies, Cairo: Book World.

Schulz, W., Ainley, J., Fraillon, J., Losito, B., \& Kerr, D. (20o8). International Civic and Citizenship Education Study: Assessment Framework. Amsterdam: International Education Association. 
TCI (2017). Elementary Social Studies: Interactive Programs. Mountain View, CA: Teachers' Curriculum Institute.

Tonga, D. (2016). Social Studies Education in Turkey, and Islam. International Online Journal of Educational Sciences, 8 (1) Online.

Wade, R. (2008). Service-learning - Handbook of Research in Social Studies Education. New York: Routledge.

Youssef, A. (2015). Basic Educational Competencies of the Teachers of National Education Degree of Practice and the Need for Training: A Field Study in the Schools of Damascus, Journal of the Federation of Arab Universities for Education and Psychology, 13 (22), 91-116. 